\title{
Crystal Structure of Naturally Occurring Mercury(II) Amidonitrate*
}

\author{
CHARLES J. RANDALL, DONALD R. PEACOR, \\ AND ROLAND C. ROUSE \\ Department of Geological Sciences, University of Michigan, \\ Ann Arbor, Michigan 48109 \\ AND PETE J. DUNN \\ Department of Mineral Sciences, Smithsonian Institution, \\ Washington, D.C. 20560
}

Received May 5, 1981; in revised form October 30, 1981

\begin{abstract}
A naturally-occurring mercuroammonium compound from Pitkin County, Colorado, is shown to be the natural analog of synthetic $\mathrm{HgNH}_{2} \mathrm{NO}_{3}$. The crystals are isometric, $P 4_{1} 32$ or $P 4_{3} 32$, with $a=10.254$ (1) $\AA$ and twelve formula weights per cell. Using 437 symmetry-independent reflections, the crystal structure was partially determined and refined to a residual of 0.090 . The positions of the $\mathrm{Hg}$ atoms and the $\mathrm{N}$ and $\mathrm{O}$ atoms of the nitrate group were determined, but the amide ion could not be located, probably due to positional disorder. The structure contains mercury atoms arranged in equilateral triangles 3.421 (1) $\AA$ on a side. These triangles are linked through shared vertices into helical chains wound around the fourfold screw axes. Similar triangular units occur in other inorganic $\mathrm{Hg}$ (II) compounds. The distortion of the nitrate ion from trigonal planar symmetry is also discussed.
\end{abstract}

\section{Introduction}

In 1977 crystals of an unidentified, naturally occurring mercury compound were supplied to the authors by Mr. Robert Lewandowski, who had collected them at an abandoned mine in Pitkin County, Colorado. The powder X-ray diffraction pattern was unlike that of any known mineral, but was essentially identical to that reported by Hayek and Inama ( 1 ) for synthetic mercury(II) amidonitrate, $\mathrm{HgNH}_{2} \mathrm{NO}_{3}$. In this paper we report the results of a chemical and single-crystal X-ray diffraction study of the natural analog of $\mathrm{HgNH}_{2} \mathrm{NO}_{3}$, together with a partial solution of its crystal structure.

* Contribution No. 369 from the Mineralogical Laboratory, Department of Geological Sciences, University of Michigan, Ann Arbor, Mich.

\section{Crystal Data}

Natural $\mathrm{HgNH}_{2} \mathrm{NO}_{3}$ occurs as pale yellow, almost colorless, isometric crystals up to several millimeters in size. Forms present are the octahedron and dodecahedron, with the former predominant. For comparison, the synthetic crystals are reported to be "yellowish rhombic dodecahedra" (1). The density of the natural mineral, which was measured with a Berman balance using a temperature correction, is $5.03 \mathrm{~g} / \mathrm{cm}^{3}$ compared to a calculated value of $5.15 \mathrm{~g} / \mathrm{cm}^{3}$. The Mohs hardness is $2 \frac{1}{2}$ to 3 and the refractive index in sodium light is 1.81 .

Weissenberg and precession photographs revealed Friedel symmetry and extinctions consistent only with space groups $P 4_{1} 32$ and $P 4_{3} 32$. The unit cell parameter, which 
TABLE I

Comparison of Powder X-Ray Diffraction Data for Natural and Synthetic $\mathrm{HgNH}_{2} \mathrm{NO}_{3}$

\begin{tabular}{|c|c|c|c|c|c|c|c|c|c|c|c|}
\hline \multicolumn{2}{|c|}{ Synthetic ${ }^{a}$} & \multicolumn{4}{|c|}{ Natural $^{b}$} & \multicolumn{2}{|c|}{ Synthetic $^{a}$} & \multicolumn{4}{|c|}{ Natural $^{b}$} \\
\hline$d_{\text {obsd }}$ & $I_{\mathrm{obsd}}$ & $d_{\mathrm{obsd}}$ & $d_{\text {calcd }}$ & $h k l$ & $I_{\text {obsd }}$ & $d_{\mathrm{obsd}}$ & $I_{\text {obsd }}$ & $d_{\mathrm{obsd}}$ & $d_{\text {caled }}$ & $h k l$ & $I_{\text {obsd }}$ \\
\hline 7.32 & 20 & 7.24 & 7.25 & 011 & 80 & 1.76 & 16 & 1.758 & 1.758 & 035,334 & 20 \\
\hline 5.95 & 20 & 5.92 & 5.92 & 111 & 80 & 1.737 & 20 & 1.735 & 1.733 & 135 & 30 \\
\hline 4.58 & 17 & 4.57 & 4.59 & 012 & 50 & & & 1.602 & 1.601 & $045,125,344$ & 50 \\
\hline 3.42 & 47 & 3.412 & 3.418 & 122 & 60 & & & 1.581 & 1.582 & 145 & 10 \\
\hline 3.09 & 40 & 3.087 & 3.092 & 113 & 40 & & & 1.564 & 1.564 & 335 & 2 \\
\hline 2.96 & 100 & 2.953 & 2.960 & 222 & 100 & & & 1.546 & 1.546 & 226 & 10 \\
\hline 2.85 & 8 & 2.838 & 2.844 & 023 & 2 & & & 1.529 & 1.529 & 036,245 & 2 \\
\hline 2.74 & 60 & 2.741 & 2.741 & 123 & 60 & & & 1.463 & 1.465 & 236 & 40 \\
\hline 2.56 & 47 & 2.562 & 2.563 & 004 & 60 & & & 1.449 & 1.450 & $017,055,345$ & 10 \\
\hline 2.48 & 45 & 2.487 & 2.487 & 223,014 & 60 & & & 1.408 & 1.408 & 027,146 & 5 \\
\hline 2.42 & 17 & 2.416 & 2.417 & 114,033 & 30 & & & 1.395 & 1.395 & $127,255,336$ & 40 \\
\hline 2.35 & 33 & 2.349 & 2.352 & 133 & 40 & & & 1.335 & 1.335 & 137,355 & 1 \\
\hline 2.24 & 25 & 2.237 & 2.238 & 124 & 40 & & & 1.312 & 1.313 & 346 & 1 \\
\hline 2.18 & 23 & 2.185 & 2.186 & 233 & 40 & & & 1.302 & 1.302 & 156,237 & 20 \\
\hline 2.10 & 3 & & & & & & & 1.272 & 1.272 & 018,256 & 20 \\
\hline 2.05 & 15 & 2.050 & 2.051 & 034 & 5 & & & 1.201 & 1.200 & 038,166 & 1 \\
\hline 2.01 & 20 & 2.009 & 2.011 & 134,015 & 40 & & & 1.192 & 1.192 & $057,138,347$ & 2 \\
\hline 1.97 & 9 & 1.974 & 1.973 & 333,115 & 5 & & & 1.185 & 1.184 & 157,555 & 1 \\
\hline 1.90 & 5 & & & & & & & 1.162 & 1.161 & 257 & 2 \\
\hline 1.87 & 12 & 1.873 & 1.872 & 125 & 5 & & & 1.140 & 1.139 & 148,366 & 5 \\
\hline 1.815 & 15 & 1.812 & 1.813 & 044 & 20 & & & 1.088 & 1.087 & $058,257,348$ & 15 \\
\hline 1.79 & 30 & 1.784 & 1.785 & 144 & 40 & & & 1.002 & 1.001 & $1 \cdot 2 \cdot 10,458$ & 20 \\
\hline
\end{tabular}

${ }^{a}$ Diffractometer data from Hayek and Inama $(I)$.

${ }^{b}$ Gandolfi data from a sample of the natural compound.

was refined by least-squares from the powder X-ray diffraction data in Table $I$, is 10.254(1) $\AA$. The powder data were obtained with a 114.6-mm Gandolfi camera, Ni-filtered $\mathrm{CuK \alpha}$ radiation, a polycrystalline sample, and an NBS silicon $(a=$ $5.43088 \AA$ ) internal standard. Reflection intensities were visually estimated and indexing was carried out with the aid of the single-crystal intensities. There are twelve formula weights per unit cell. The isometric unit cell and powder data are essentially identical to those of the synthetic phase ( $I$ ) and are easily distinguished from those of all other mercury compounds listed in the Powder Diffraction File.

A chemical analysis of the natural crystals, performed by a commercial analytical laboratory, yielded $71.9 \% \mathrm{Hg}$ and $7.5 \%$ total $\mathrm{N}$. The latter was reported to be present in three oxidation states: $4.3 \% \mathrm{~N}^{5+}, 0.2 \%$ $\mathrm{N}^{3+}$, and $3.0 \% \mathrm{~N}^{3-}$. Thermogravimetric analysis with simultaneous analysis of the volatile components by mass spectrometry revealed only $\mathrm{NO}_{3}$ and $\mathrm{NH}_{3}$, which was consistent with the reported major oxidation states of the nitrogen (R. A. Ramik, Royal Ontario Museum, personal communication). Stoichiometric $\mathrm{HgNH}_{2} \mathrm{NO}_{3}$ contains $71.99 \% \mathrm{Hg}$ and $10.05 \% \mathrm{~N}$, and while the former figure agrees well with the chemical analysis, the latter does not. A crystal structure analysis of the natural phase was therefore initiated in hopes of resolving this apparent discrepancy in the nitrogen content. 


\section{Structure Solution and Refinement}

The crystal selected for intensity measurcment was an irregular fragment $0.40 \times$ $0.19 \times 0.08 \mathrm{~mm}$ in size and mounted on the [110] axis. Intensities of 1653 reflections having $\sin \theta \leq 0.460$ were measured with a Supper-Pace diffractometer system using Weissenberg equi-inclination geometry, Mo $K \alpha$ radiation, a scintillation counter, and a graphite monochromator. The scanning rate was $2 \%$ min and $30-s e c$ background counts were taken on both sides of each peak. Corrections were made for Lorentz, polarization, and absorption $\left(\mu_{1}=434\right.$ $\mathrm{cm}^{-1}$ ) effects. Unobserved reflections were assigned estimated intensities according to the procedure of Prewitt and Burnham (2). The final set of structure factor amplitudes numbered 437 after averaging symmetryequivalent reflections.

A three-dimensional Patterson synthesis was then prepared, the peaks of which led to the assignment of the mercury atoms to equipoint $12 d$ of space group $P 4_{1} 32$ with $x$ $=0.094$. Least-squares refinement of the positional and thermal parameters of the mercury atoms converged to a residual, defined as $\left.\Sigma|| F\right|_{\text {obsd }}-|F|_{\text {calcd }} / \Sigma|F|_{\text {obsd }}$, of 0.13 . The program RFINE 2 (3), neutral atom scattering factors (4), anomalous dispersion corrections (5), and Cruickshank's weighting scheme (6) were used in the refinement.

Since stoichiometric $\mathrm{HgNH}_{2} \mathrm{NO}_{3}$ contains 24 nitrogen atoms, which must be equally divided between the nitrate and amide groups, these atoms must occupy equipoint $12 d$ or some combination of $8 c$ with $4 a$ and $4 b$. Moreover, $\mathrm{Br}^{-}$and $\mathrm{NO}_{3}^{-}$are approximately the same size, and hence the distance $\mathrm{Hg}-\mathrm{N}^{5+}$ in $\mathrm{HgNH}_{2} \mathrm{NO}_{3}$ should be similar to the $\mathrm{Hg}-\mathrm{Br}$ distance in cubic $\mathrm{HgNH}_{2} \mathrm{Br}$ (7). A number of structural models were then devised assuming $\mathrm{Hg}$ $\mathrm{N}^{5+}$ and $\mathrm{Hg}-\mathrm{N}^{3-}$ distances of approximately 3.1 and $2.2 \AA$, respectively, the lat- ter value also being taken from the structure of cubic $\mathrm{HgNH}_{2} \mathrm{Br}$. These led to the conclusion that both $\mathrm{N}^{5+}$ and $\mathrm{N}^{3-}$ must occupy 12 -fold positions, for if either were to occupy one of the fourfold equipoints, it would necessitate $\mathrm{Hg}-\mathrm{N}$ distances of 3.87 Ă or greater.

The interatomic vector sets predicted by the most reasonable of the trial models were then compared to the Patterson maps. The $\mathrm{Hg}-\mathrm{Hg}$ vectors accounted for all sets of peaks except one, and that one corresponded to the $\mathrm{Hg}-\mathrm{N}^{5+}$ vector set predicted by one model of the nitrate group position. Subsequent electron density and difference electron density syntheses revealed that the oxygen atoms of the nitrate group occupied equipoints $12 d$ and $24 e$. Refinement of positional and thermal parameters for $\mathrm{Hg}, \mathrm{N}^{5+}$, and $\mathrm{O}$ atoms produced the final values shown in Table II.

Unfortunately, all attempts to similarly locate the position of the amide group failed. No unambiguous peaks not explainable as mercury or nitrate group atoms could be found on the electron density and difference electron density maps, and none of the possible amide group positions tested by structure factor calculations produced an improvement in the value of the residual. It was therefore concluded that the amide ion is positionally disordered in the structure of $\mathrm{HgNH}_{2} \mathrm{NO}_{3}$.

The final value of the residual for all

TABLE II

ATOMIC COORDINATES AND ISOTROPIC Temperature Factors $\left(\AA^{2}\right)$

\begin{tabular}{lcclll}
\hline & \multicolumn{1}{c}{$x$} & \multicolumn{1}{c}{$y$} & \multicolumn{1}{c}{$z$} & \multicolumn{1}{c}{$B$} \\
\hline $\mathrm{Hg}$ & $12 d$ & $\frac{1}{8}$ & $0.0937(2)$ & $0.3437(2)$ & $1.60(2)$ \\
$\mathrm{N}$ & $12 d$ & $\frac{1}{8}$ & $0.844(5)$ & $0.094(5)$ & $1.9(5)$ \\
$\mathrm{O}(1)$ & $12 d$ & $\frac{1}{8}$ & $0.754(8)$ & $0.004(8)$ & $3.8(8)$ \\
$\mathrm{O}(2)$ & $24 e$ & $0.018(4)$ & $0.873(5)$ & $0.131(4)$ & $5.5(8)$ \\
\hline
\end{tabular}

Note. Estimated standard deviations are given in parentheses. 
reflections is 0.090 . This rather high value is due in part to the absence of the amide group from the structure factor calculations and in part to absorption error. The transmission factors ranged from 0.03 to 0.08 and were imprecise for symmetry-equivalent reflections due to the irregular crystal shape. The final set of observed and calculated structure factors appears in Table III. ${ }^{1}$ Interatomic distances and angles with their standard errors appear in Table IV. These were calcuated by the program OR FFE (8) using the atomic parameter variance-covariance matrix from the final cycle of refinement.

\section{Discussion}

Any discussion of the mercury amidonitrate structure is necessarily limited by our ignorance of the positions of the amide groups. Nevertheless, some conclusions can be drawn concerning the coordination of the mercury atoms based upon the known crystal chemical behavior of divalent mercury.

The structure solution reveals each mercury atom to be surrounded by five nitrate ions, but only two oxygens of the latter can be considered to be coordinated to the metal. These are the two $O(2)$ atoms at 2.77(4) $\AA$ (Table IV); all other $\mathrm{Hg}-\mathrm{O}$ distances exceed $3.20 \AA$, which is greater than the sum of the van der Waals radii, $3.0 \AA$ $(9,10)$. The $2.77-\AA$ distance is longer than the sum of the ionic radii of $\mathrm{Hg}^{2+}$ and $\mathrm{O}^{2-}$

\footnotetext{
${ }^{1}$ See NAPS document No. 03944 for 3 pages of supplementary material. Order from ASIS/NAPS, Microfiche Publications, P.O. Box 3513, Grand Central Station, New York, N.Y. 10163. Remit in advance $\$ 4.00$ for microfiche copy or for photocopy, $\$ 7.75$ for up to 20 pages plus $\$ .30$ for each additional page. All orders must be prepaid. Institutions and organizations may order by purchase order. However, there is a billing and handling charge for this service of $\$ 15$. Foreign orders add $\$ 4.50$ for postage and handling, for the first 20 pages, and $\$ 1.00$ for additional 10 pages of material. Remit $\$ 1.50$ for postage of any microfiche orders.
}

TABLE IV

Selected Interatomic Distances ( $(\AA)$ AND ANGLES ( $\left.{ }^{\circ}\right)$

\begin{tabular}{|c|c|c|c|c|}
\hline \multicolumn{5}{|c|}{ Mercury-oxygen } \\
\hline $\mathrm{Hg}-\mathrm{O}(2)$ & $2.77(4)$ & $2 x$ & $\mathrm{O}(2)-\mathrm{Hg}-\mathrm{O}(2)$ & $155(2)$ \\
\hline$-O(2)$ & $3.23(5)$ & $2 x$ & & \\
\hline$-O(2)$ & $3.33(5)$ & $2 x$ & & \\
\hline$-O(1)$ & $3.422(3)$ & $2 x$ & & \\
\hline \multicolumn{5}{|c|}{ Mercury-nitrogen } \\
\hline $\mathrm{Hg}-\mathrm{N}$ & $3.63(8)$ & & & \\
\hline$-\mathrm{N}$ & $3.65(4) 2$ & $2 \times$ & & \\
\hline$-\mathrm{N}$ & $3.68(3) 2$ & $2 \times$ & & \\
\hline \multicolumn{5}{|c|}{ Mercury triangles } \\
\hline $\mathrm{Hg}-\mathrm{Hg}$ & $3.421(1)$ & $4 x$ & $\mathrm{Hg}-\mathrm{Hg}-\mathrm{Hg}$ & $124.16(3) 2 \times$ \\
\hline & & & $\mathrm{Hg}-\mathrm{Hg}-\mathrm{Hg}$ & $60.000(1) 2 \times$ \\
\hline & & & $\mathrm{Hg}-\mathrm{Hg}-\mathrm{Hg}$ & $124.77(4)$ \\
\hline & & & $\mathrm{Hg}-\mathrm{Hg}-\mathrm{Hg}$ & $172.40(5)$ \\
\hline \multicolumn{5}{|c|}{ Nitrate group } \\
\hline $\mathrm{N}-\mathrm{O}(2)$ & $1.20(5) 2$ & $2 \times$ & $\mathrm{O}(2)-\mathrm{N}-\mathrm{O}(2)$ & $133(8)$ \\
\hline$-O(1)$ & $1.30(12)$ & & $\mathrm{O}(2)-\mathrm{N}-\mathrm{O}(1)$ & $144(4) 2 x$ \\
\hline Mean & 1.23 & & Mean & 120 \\
\hline $\mathrm{O}(1)-\mathrm{O}(2)$ & $2.10(10)$ & $2 x$ & & \\
\hline$O(2)-O(2)$ & $2.21(9)$ & & & \\
\hline Mean & 2.14 & & & \\
\hline \multicolumn{5}{|c|}{ Oxygen-oxygen } \\
\hline$O(1)-O(2)$ & $3.02(6)$ & $2 x$ & & \\
\hline$O(2)-O(2)$ & $3.10(4)$ & $2 \times$ & & \\
\hline$O(1)-O(1)$ & $3.24(19)$ & $2 \times$ & & \\
\hline $\mathrm{O}(2)-\mathrm{O}(2)$ & $3.25(8)$ & $2 \times$ & & \\
\hline
\end{tabular}

Note. Estimated standard deviations are given in parentheses. Existence of two or four equivalent distances is indicated by $2 x$ or $4 \times$, respectively.

(11), which is $2.54 \AA$ assuming the highest practical coordination (eightfold) for mercury.

According to Grdenic $(9,10) \mathrm{Hg}(\mathrm{II}) \mathrm{com}-$ monly forms two (digonal) or three (trigonal planar) short bonds, plus a number of longer contacts, which complete a distorted tetrahedral, trigonal pyramidal, trigonal bipyramidal, or octahedral coordination polyhedron around the metal atom. In the octahedral case, distorted $\mathrm{HgO}_{6}$ octahedra typically contain two very short $\mathrm{Hg}-\mathrm{O}$ bonds about $2.0 \AA$ in length and four distant oxygens at 2.7 to $2.9 \AA(12)$. It is known that cubic and orthorhombic $\mathrm{HgNH}_{2} \mathrm{Br}$, $\mathrm{HgNH}_{2} \mathrm{Cl}$, and $\mathrm{Hg}\left(\mathrm{NH}_{3}\right)_{2} \mathrm{Br}$ all contain mer- 
cury in distorted octahedral coordination with amide groups acting as the two "close" ligands (13). If the same were true for $\mathrm{HgNH}_{2} \mathrm{NO}_{3}$, the $\mathrm{O}(2)$ atoms at $2.77 \AA$ would be members of the "distant" ligand set, while the unlocated amide ions would function as the two close, strongly bonded ligands. Additional oxygen or amide ions would complete the octahedron. Although octahedral coordination of mercury seems a reasonable hypothesis in this structure, all that can safely be said is that the actual coordination is not tetrahedral, i.e., $20+$ $2 \mathrm{NH}_{2}$. The angle $\mathrm{O}(2)-\mathrm{Hg}-\mathrm{O}(2)$ is $155(2)^{\circ}$, which is far removed from the tetrahedral angle of $109^{\circ} 28^{\prime}$.

The most interesting feature of the known structure is the helical chains of vertex-sharing equilateral triangles of mercury atoms wound around the fourfold screw axes (Fig. 1). Each $\mathrm{Hg}$ is 3.421(1) $\AA$ from four other mercury atoms (Fig. 2), the positions of the five atoms forming a pair of vertex-sharing equilateral triangles such that an edge of one triangle is nearly colinear with the edge of the other. The angle

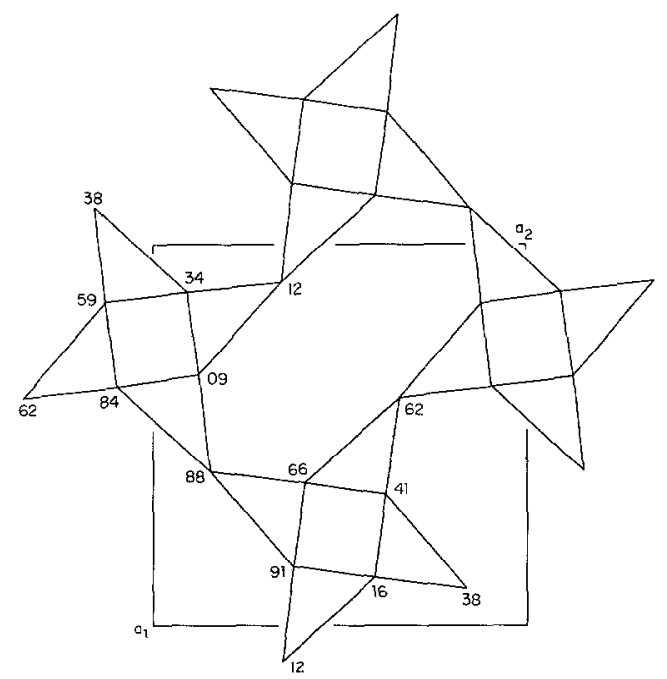

FIG. 1. Projection of part of the structure of $\mathrm{HgNH}_{2} \mathrm{NO}_{3}$ on (001) showing the helical chains of equilateral mercury triangles. The numbers are the $z$ coordinates of the mercury atoms $\times 100$.

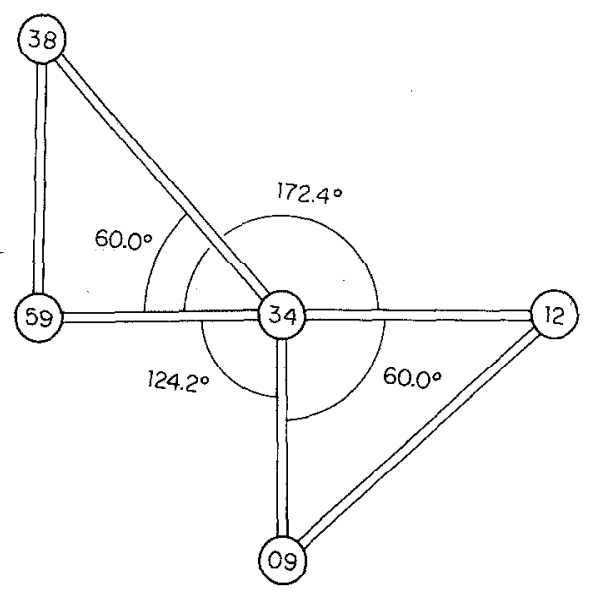

FIG. 2. Projection on (001) of a pair of equilateral mercury triangles showing the interatomic angles. The numbers within the circles are the $z$ coordinates of the atoms $\times 100$.

$\mathrm{Hg}-\mathrm{Hg}-\mathrm{Hg}$ is $172.40(5)^{\circ}$. Each pair of triangles then shares vertices with two similar pairs forming a helical chain. Adjacent chains are linked to one another at intervals through more shared vertices (Fig. 1).

The equilateral triangle of mercury atoms having $\mathrm{Hg}-\mathrm{Hg}$ distances in the range $3.5 \pm$ $0.1 \AA$ appears to be a recurrent structural element among the inorganic compounds of divalent mercury. Two previously described representative examples are $\mathrm{Hg}_{3} \mathrm{~S}_{2} \mathrm{Cl}_{2}$ (14), which contains helical chains of triangles similar to those in $\mathrm{HgNH}_{2} \mathrm{NO}_{3}$, and $\mathrm{Hg}_{3} \mathrm{OCl}_{4}$ (15), which contains isolated $\mathrm{Hg}_{3}$ triangles. The mineral terlinguaite, $\mathrm{Hg}_{4} \mathrm{O}_{2} \mathrm{Cl}_{2}$ (16), contains triangular $\mathrm{Hg}_{3}$ groups which deviate from the above pattern in that the $\mathrm{Hg}-\mathrm{Hg}$ distance is a very short $2.708 \AA$. This is actually shorter than the 2.999- $\AA$ nearest-neighbor distance in $\alpha$-mercury $(10)$. While the short $\mathrm{Hg}-\mathrm{Hg}$ distance in terlinguaite suggests metal-metal bonding within the triangles (16), no such phenomenon is indicated in $\mathrm{HgNH}_{2} \mathrm{NO}_{3}$. The $\mathrm{Hg}-\mathrm{Hg}$ separation of $3.421 \AA$ is close to the second nearestneighbor distance ( $3.466 \AA$ ) in $\alpha$-mercury. Moreover, $3.42 \AA$ is precisely the separa- 
tion expected between two adjacent but nonbonded mercury atoms according to Glidewell's concept of nonbonded atomic radii (17).

Turning to the nitrate ions, these groups show some distortion from the ideal trigonal planar configuration. Unfortunately, the exact extent of this distortion is uncertain due to the rather large errors in the bond parameters (Table IV). The $\mathrm{N}-\mathrm{O}$ distances are $1.30(12)$ and $1.20(5) \AA$ (twice) for a mean of $1.23 \AA$, which compares well to the grand mean of $1.250 \AA$ for all nitrate compounds surveyed by Baur (18). The angles $\mathrm{O}-\mathrm{N}-\mathrm{O}$ are $133(8)^{\circ}$ and $114(4)^{\circ}$ (twice) for a mean of $120^{\circ}$, which is the ideal value of this angle. The sum of the $\mathrm{O}-\mathrm{N}-\mathrm{O}$ angles is $360.00^{\circ}$ if three decimal places are carried in the calculation, indicating that the nitrate group in $\mathrm{HgNH}_{2} \mathrm{NO}_{3}$ is planar within error of measurement.

\section{Acknowledgments}

The authors wish to thank Mr. Robert Lewandowski for donating the crystals used in this study. Thanks are also due to Mr. Robert A. Ramik of the Royal Ontario Museum for the thermogravimetric and mass spectrometric analyses and to Miss Catherine Ebelke for her helpful translations of scveral foreign language papers.

\section{References}

1. E. Hayek and P. Inama, Monatsh. Chem. 96, 1454 (1965).
2. C. T. Prewitt and C. W. Burnham, Amer. Mineral. 51, 956 (1966)

3. L. W. Finger, "RFINE 2. A Fortran IV Computer Program for Structure Factor Calculation and Least-Squares Refinement of Crystal Structures," Geophysical Laboratory, Washington, D.C. (1972).

4. P. A. Doyle and P. S. Turner, Acta Crystallogr. Sect. A 24, 390 (1968).

5. D. T. Cromer and D. Liberman, J. Chem. Phys. 53, 1891 (1970).

6. D. W. J. Cruickshank, in "Computing Methods in Crystallography"' ( J. S. Rollett, Ed.), Chap. 14, Pergamon, Oxford (1965).

7. W. RüdorfF And K. Brodersen, $Z$. Anorg. Allg. Chem. 270, 145 (1952).

8. W. R. Busing, K. O. Martin, and H. A. Levy, "OR FFE. A Fortran Crystallographic Function and Error Program," Oak Ridge National Laboratory, Oak Ridge, Tenn. (1964).

9. D. Grdenic, Quart. Rev. Chem. Soc. 19, 303 (1965).

10. D. GRDENIC, in "Handbook of Geochemistry" (K. H. Wedepohl, Ed.), Chap. 80, SpringerVerlag, Berlin/New York (1969).

11. R. D. Shannon, Acta Crystallogr. Sect. A 32, 751 (1976).

12. M. B. Hursthouse, Mol. Struct. Diffr. Methods 2, 412 (1974).

13. D. Breitinger and K. Brodersen, Angew. Chem. Int. Ed. Engl. 9, 357 (1970).

14. K. Aurivillius, Ark. Kemi 26, 497 (1967).

15. K. Aurivillius, Ark. Kemi 22, 537 (1964).

16. K. Aurivillius and L. Folkmarson, Acta Chem. Scand. 22, 2529 (1968).

17. C. Glidewell, Inorg. Chim. Acta 36, 135 (1979).

18. W. H. BAUR, in "Handbook of Geochemistry" (K. H. Wedepohl, Ed.), Chap. 7, Springer-Verlag, Berlin/New York (1974). 